\title{
Meeting of Initiative Group for Central European Hepatologic Collaboration (CEHC)
}

\section{Warsaw, 19-21 November 2015}

The Meeting of Initiative Group for Central European Hepatologic Collaboration (CEHC) took place between 19 and 21 November 2015 in Warsaw. The idea was developed a few months earlier, during informal discussions between hepatologists from the Czech Republic, Hungary, Poland and Slovakia. All these countries located in the heart of the Europe demonstrate similar achievements and problems in health care and scientific development affected by a similar history and culture. We considered the name of "Hepatological Visegrad Group", but finally decided not to include political issues into our collaboration and to open possible involvement of hepatologists from other countries of the region. According to definitions of the Organization for Economic Co-operation and Development (OECD) and World Bank, this region of the world is called Central Europe and therefore we decided to provide the name of the Central European Hepatologic Collaboration.

The aim of CEHC is to search for possible collaboration between physicians and medical scientists involved in educational and scientific activities related to liver diseases. Eighteen representatives of hepatologic associations/sections from the Czech Republic, Hungary, Poland and Slovakia attended the meeting, to discuss possible collaboration. Five major topics from each country were presented and discussed:

1. Epidemiology of viral hepatitis and screening programs for HCV in the region.

2. Access to new therapeutic options for chronic hepatitis $\mathrm{C}$.

3. Liver surgery and transplantation.

4. Evaluation of hepatic fibrosis and access to non-invasive tests.

5. Topics of special interest in particular countries.

Five articles corresponding to these topics are published in the current issue of the Clinical and Experimental Hepatology.

Prof. Robert Flisiak

President of Polish Association for the Study of the Liver Vice-president of Polish Association of Epidemiologists and Infectiologists Head of the Department of Infectious Diseases and Hepatology, Medical University of Bialystok 